\title{
Impairment of Spatial Learning and Hippocampal Synaptic Potentiation in c-kit Mutant Rats
}

\author{
Toshihiko Katafuchi, ${ }^{1,4}$ Ai-Jun Li, ${ }^{1,3}$ Seiichi Hirota, ${ }^{2}$ Yukihiko Kitamura, ${ }^{2}$ \\ and Tetsuro Hori ${ }^{1}$ \\ ${ }^{1}$ Department of Integrative Physiology, Graduate School of Medical Sciences Kyushu University, Fukuoka 812-8582 Japan; \\ ${ }^{2}$ Department of Pathology, Osaka University Graduate School of Medicine, Suita 565 Japan
}

\begin{abstract}
The c-kit receptor tyrosine kinase encoded by the white-spotting $(W)$ gene is highly expressed in rat hippocampal CA1-CA4 regions. We found an impaired spatial learning and memory in homozygous c-kit (Ws/ $W s$ ) mutant rats that have a 12-base deletion in the tyrosine kinase domain of the c-kit gene and a very low kinase activity. Electrophysiological studies in hippocampal slices revealed that the long-term potentiation (LTP) induced by the tetanic stimulation $(100 \mathrm{~Hz}, 1 \mathrm{sec})$ in the mossy fiber (MF)-CA3 pathway, but not in the Schaffer collaterals/commissural-CA1 pathway, was significantly reduced in c-kit mutants compared with wild-type $(+/+)$ rats. The paired-pulse facilitation (PPF) was measured before the tetanus and after the establishment of the LTP in each slice. The initial PPF in the MF-CA3 pathway positively correlated with the amplitude of the LTP in the wild-type rats but not in the $c$-kit mutant rats. Furthermore, they failed to show the normal characteristics observed in the MF-CA3 pathway of $+/+$ rats; that is, the negative correlation between the initial PPF and the changes in PPF measured after the LTP. These findings suggest an involvement of SCF/c-kit signaling in hippocampal synaptic potentiation and spatial learning and memory.
\end{abstract}

The $c$-kit receptor is a member of a receptor tyrosine kinase family that is structurally related to the receptors for a colony-stimulating factor-1 (CSF-1) and platelet-derived growth factor (PDGF) (Qui et al. 1988). This receptor is encoded by the proto-oncogene $c$-kit located at the white spotting $(W)$ locus in rodents (Chabot et al. 1988). The ligand for the $c$-kit receptor tyrosine kinase has been designated as a stem cell factor (SCF), mast cell growth factor, or c-kit ligand, which is mapped to the Steel ( $S l$ ) locus (Huang et al. 1990; Zsebo et al. 1990a). The c-kit receptors are expressed on the cell surface of erythrocytes, mast cells, melanocytes, germ cells, and the precursors of these cells, whereas cells surrounding them such as fibroblasts produce SCF. It has been shown that SCF plays an important role in the differentiation and proliferation of these cells working in a paracrine fashion (Williams et al 1992). Furthermore, SCF is synthesized as membrane bound forms as well as soluble forms (Zsebo et al. 1990b), suggesting that works as a cell-adhesion molecule (Adachi et al. 1992).

The gene expression of $c$-kit receptors and SCF has also been demonstrated in the central nervous system (CNS) of mouse embryo (Matsui et al. 1990). The $c$-kit/SCF signaling

${ }^{3}$ Present address: Cell Biology Laboratory, National Institute of Bioscience and Human Technology, 1-1 Higashi, Tsukuba, Ibaraki 305, Japan.

${ }^{4}$ Corresponding author.

E-MAIL kataf@physiol.med.kyushu-u.ac.jp; FAX 81-92-6426093.

Article and publication date are at www.learnmem.org/cgi/doi/ $10.1101 / \mathrm{lm} .33900$. is shown to be involved in cell migration, proliferation, differentiation of neural crest-derived melanocyte precursors (Langtimm-Sedlak et al. 1996) and outgrowth of neurites in dorsal root ganglia neurons of mouse embryos (Hirata et al. 1993). Furthermore, in adult mice and rats, mRNA for SCF is strongly expressed in the neurons of the entorhinal cortex and the granule cells in the dentate gyrus, whereas the transcripts of $c$-kit are found in pyramidal cells in the area CA1-CA4, among which the expression in the CA3 region is the strongest (Motro et al. 1991; Hirota et al. 1992; Wong and Licinio 1994). The cellular localization of SCF and $c$-kit proteins in the adult mouse hippocampus was further characterized by an immunocytochemical study (Zhang and Fedoroff 1997). In the MF-CA3 pathway, SCF was found in cell bodies of the granule cells in the dentate gyrus, whereas heavy immunostaining for c-kit was localized in the dendrites of pyramidal neurons in the stratum radiatum. These findings raise a possibility that $c$-kit/SCF signaling is involved in the synaptic transmission in the hippocampus and possibly in the hippocampal-dependent spatial learning and memory. In fact, mice carrying heterozygous mutation at $S l$ locus $\left(S l / S l^{d}\right)$ have a deficit in hippocampal learning and a selective reduction of baseline synaptic transmission between the dentate gyrus and CA3 pyramidal cells, although they exhibit normal long-term potentiation (LTP) in this hippocampal pathway (Motro et al. 1996). This mutation is characterized by the lack of the membrane-bound form of SCF, but the soluble SCF is preserved (Flanagen et al. 1991). It is unknown whether or not

LEARNING \& MEMORY 7:383-392 @ 2000 by Cold Spring Harbor Laboratory Press ISSN1072-0502/00 \$5.00

$$
\begin{array}{lllllllllllllll}
\text { L } & E & A & R & N & I & N & G & \mathcal{Z} & M & E & M & O & R & Y \\
\text { www.learnmem.org } & & &
\end{array}
$$


the dissociation between spatial memory and LTP is related to the presence of the soluble SCF and intact $c$-kit receptors in $S l / S l^{d}$ mice.

In the present study, we investigated the possible role of $c$-kit/SCF signaling in hippocampal learning behavior and synaptic plasticity using homozygous $c$-kit receptor mutant $(W s / W s)$ rats having a 12-base deletion in the tyrosine kinase domain of the $c$-kit gene (Tsujimura et al. 1991) and a very low kinase activity (Tei et al. 1994). The Morris water maze task was used to test a hippocampal-dependent spatial learning and memory. Extracellular field potentials were recorded from the Schaffer collaterals/commissural (S/C)CA1 and the mossy fiber (MF)-CA3 pathways in hippocampal slices. We then examined the paired-pulse facilitation (PPF), LTP, and the changes in PPF after the establishment of LTP.

\section{RESULTS}

\section{Spatial Learning and Memory}

A hidden platform version of the Morris water maze task was applied to $W s / W s(n=6)$ and $+/+(n=6)$ rats. Each animal received four trials (one block) twice a day for two consecutive days. The latency to find the platform is depicted in Figure 1A. There was an overall significant differ-
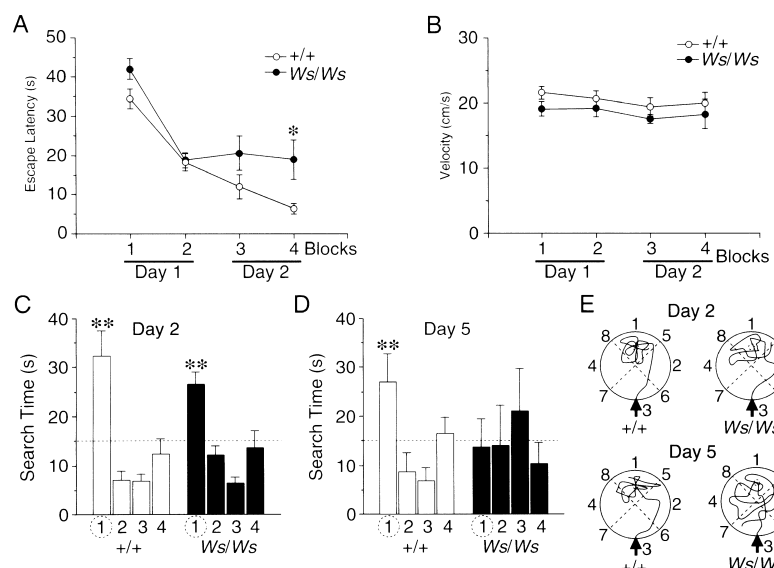

E

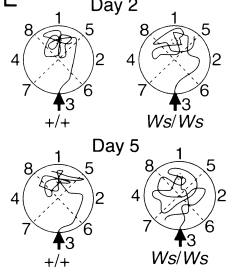

Figure 1 Performance of rats in the Morris maze task. (A) Ws/Ws mutant $(n=6)$ and $+/+$ control $(n=6)$ rats were trained with four blocks on two consecutive days. There was a significant difference in escape latency between mutant and control rats (two-way ANOVA, $P<0.01)$ and a post-hoc test revealed that escape latency of mutants is significantly prolonged at the fourth block (**, $P<0.05$, Bonferroni's test). (O) $+/+;(\mathbf{O}) W s / W s$. (B) The swimming velocity was not different between $W_{s} / W_{s}$ mutant and $+/+$ control rats. (C) Probe test performed just after the fourth block on day 2. Both mutant and control rats spent more time in quadrant 1 where the platform had been previously located $(* *, P<0.01$, Bonferroni's test). (O) $+/+;(0) W s / W s$. (D) Probe test performed on day 5 . Control $+/+$ rats spent significantly more time in quadrant 1 $(* *, P<0.05)$, whereas there was no significant difference in search time of each quadrant in $W s / W s$ mutant rats. $(E)$ Examples of traces for $+/+$ (left) and mutant (right) rats in the probe test performed on day 2 (top) and day 5 (bottom). ence in escape latency between mutant and control $+/+$ rats $\left(\mathrm{F}_{1,40}=26.68, P<0.01\right.$, two-way ANOVA $)$. In both groups, the escape latency remarkably decreased at the second block in comparison with the first block. However, mutant rats displayed no further improvement in the following blocks, whereas control rats showed a further decrease in escape latency over training blocks. A post-hoc test revealed that mutant rats needed significantly longer time to reach the platform at the fourth block on day 2 than control rats $(19.0 \pm 5.0$ vs. $6.5 \pm 1.4 \mathrm{sec}, P<0.05$, Bonferroni's test). Because the swimming velocity was not different between two groups throughout four blocks (Fig. 1B), the difference in escape latency was not due to the motor deficit in mutant rats.

The probe test was performed just after the fourth block (the sixteenth trial) on day 2 . The platform was removed and the animals searched for the missing platform for $60 \mathrm{sec}$. There was a significant difference in search time in both groups on day $2\left(+/+, \mathrm{F}_{3,20}=16.80, P<0.01\right.$, and $W s / W s, \mathrm{~F}_{3,20}=15.12, P<0.01$, one-way ANOVA) (Fig. 1C). A post-hoc test revealed that both groups spent significantly longer time in the quadrant that had previously contained the hidden platform (the quadrant 1) than in any other quadrants $(P<0.01$ in both groups, Bonferroni's test). However, the number crossing the trained goal position in mutant rats was significantly smaller than that in control rats $(3.8 \pm 0.5(n=6)$ vs. $5.2 \pm 0.3(n=6), P<0.05)$. Then the animals were returned to individual cages, kept there for three days and re-examined for their performance in the probe test on day 5. Control rats spent significantly longer time in quadrant 1 than in the test on day $2\left(\mathrm{~F}_{3,20}=6.08\right.$, $P<0.05$, one-way ANOVA and $P<0.01$, Bonferroni's test), but mutant rats did not show significant preference for any quadrants $\left(\mathrm{F}_{3,20}=0.48, P>0.05\right)$ (Fig. 1D). In addition, the average of the cross count of mutant rats $(1.2 \pm 0.5)$ was significantly lower than that of control rats $(4.7 \pm 0.6)$ $(P<0.01)$. These findings indicate an impairment of spatial learning and memory in $c-k i t$ mutant rats. Figure $1 \mathrm{E}$ shows examples of individual traces for each rat on day 2 (top) and day 5 (bottom).

\section{PPF}

Eighteen rats (four each for the S/C-CA1 experiment, and five each for the MF-CA3 experiment) were used for electrophysiological study.

PPF is a short-lasting increase in a second evoked excitatory postsynaptic potential (EPSP) when it is elicited shortly after the first one, and is thought to be mediated exclusively by presynaptic mechanisms. Because PPF may depend on the amplitude of the first EPSP, we adjusted the stimulus intensity so that the amplitude was almost the same between $+/+$ and mutant rats (Table 1 ). In addition, the intensity was adjusted to evoke about one-half of the maximum responses in both the CA1 and CA3 regions. The

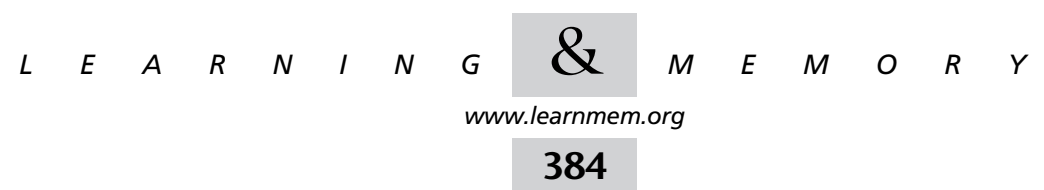


Table 1. Average Amplitude and Slope of EPSP Evoked by the First Stimulus in PPF Before and After Tetanus Stimulation

\begin{tabular}{|c|c|c|c|c|}
\hline & \multicolumn{2}{|c|}{$\begin{array}{l}\text { Average amplitude } \\
(\text { mean } \pm \text { sem, } \mathrm{mV})\end{array}$} & \multicolumn{2}{|c|}{$\begin{array}{c}\text { Average slope } \\
\text { (mean } \pm \text { sem, } \mathrm{mV} / \mathrm{msec})\end{array}$} \\
\hline & $+/+$ & Ws/Ws & +/+ & Ws/Ws \\
\hline \multicolumn{5}{|l|}{ CA1 } \\
\hline before tetanus & $0.57 \pm 0.063(10)$ & $0.55 \pm 0.064(12)$ & $-0.21 \pm 0.027(10)$ & $-0.20 \pm 0.027(12)$ \\
\hline after LTP & $1.03 \pm 0.048(10)$ & $0.95 \pm 0.099(12)$ & $-0.43 \pm 0.031(10)$ & $-0.43 \pm 0.069(12)$ \\
\hline \multicolumn{5}{|l|}{ CA3 } \\
\hline before tetanus & $0.25 \pm 0.016$ & $0.29 \pm 0.021$ & $-0.18 \pm 0.025$ & $-0.18 \pm 0.016(15)$ \\
\hline after LTP & $0.40 \pm 0.022(11)$ & $0.40 \pm 0.037(15)$ & $-0.32 \pm 0.023$ & $-0.23 \pm 0.027(15)$ \\
\hline
\end{tabular}

The number of slices examined is indicated in each parenthesis.

Interstimulus interval is $80 \mathrm{msec}$.

amplitude and the slope of population EPSP (pEPSP) in absolute values recorded from the CA1 region were larger than those recorded from the CA3 region. However, the average value of the stimulus intensity was not different between mutant $(0.34 \pm 0.07 \mathrm{~mA}, n=12)$ and controls $(0.32 \pm 0.05 \mathrm{~mA}, n=10)$ for the CA1 and CA3 experiments (mutant, $0.56 \pm 0.05 \mathrm{~mA}, n=15$; controls, $0.52 \pm 0.07 \mathrm{~mA}$, $n=11$ ). This finding suggests that the basal synaptic transmission was not impaired in mutant rats in either the CA1 or CA3 region. The average values at interstimulus intervals of $80 \mathrm{~ms}$ were not significantly different from those at $40 \mathrm{~ms}$ (data not shown). Thus, the amplitude and slope of the first pEPSP did not change during PPF trials (10 times every 10 sec at each interstimulus interval). Because it was possible that active currents from the first stimulation were still present at the 40-ms interval, which may affect the second pEPSP, the following analysis of PPF was performed at an interstimulus interval of $80 \mathrm{~ms}$.

Figure $2 \mathrm{Aa}$ and $\mathrm{Ba}$ show the averaged waveforms recorded from the areas CA1 and CA3, respectively, at a 80-ms interstimulus interval in control $(+/+$, top) and mutant $(W s / W s$, bottom) rats before tetanic stimulation. PPF in area CA1 was not significantly different between $+/+$ and mutant rats at both 40 and $80 \mathrm{~ms}$ (Bonferroni's test, $P>0.05$ ). PPF recorded from $\mathrm{CA} 3$ in mutant rats was reduced at both 40- and 80-ms interstimulus intervals compared with that in control rats (Fig. 2Bb) ( $40 \mathrm{~ms}, 141.7 \pm 9.0$ vs. $179.2 \pm 9.7 \%$, $P<0.01 ; 80 \mathrm{~ms}, 112.1 \pm 4.3$ vs. $140.8 \pm 6.5 \%, P<0.01$; $n=15$ and 11 , respectively).

\section{LTP}

After observing the PPF, a tetanic stimulation $(100 \mathrm{~Hz}, 1$ sec) with the same intensity used in the PPF study was delivered to stimulate the CA1 or CA3 synapses. Induced synaptic enhancement as measured by the slope of pEPSP at the CA1 and CA3 regions in control and mutant rats is shown in Figure 3Aa and Ba. All of the responses in the post-tetanic period were significantly greater than those of pre-tetanic stimulation baseline. The pEPSP slope of the CA1 and CA3 regions in mutant rats was significantly smaller in the post-tetanic periods of $2-47 \mathrm{~min}(P<0.01$, Bonferroni's test), and $11-60 \mathrm{~min}(P<0.01)$, respectively,

\section{A CA1}
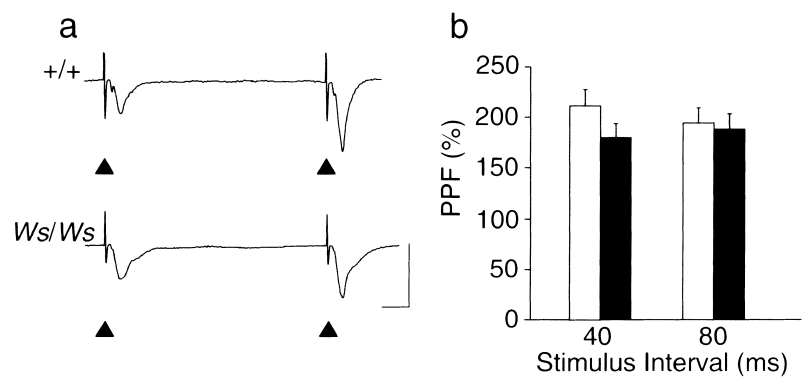

\section{B CA3}

a

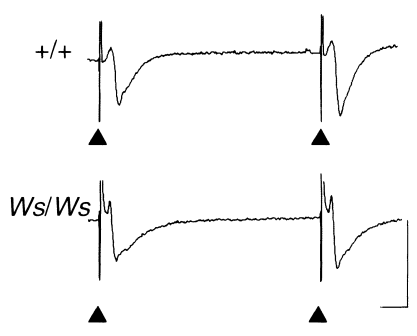

b

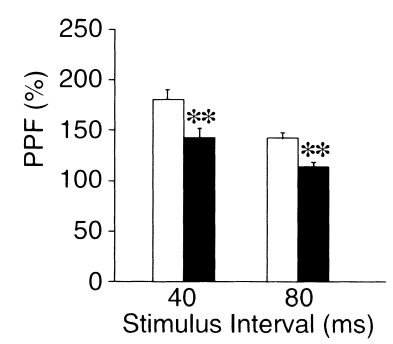

Figure 2 Paired-pulse facilitation (PPF) recorded from CA1 and CA3 regions. (Aa) Averaged waveforms of 10 traces evoked by paired pulses $(\boldsymbol{\Lambda})$ at an $80-\mathrm{ms}$ interstimulus interval obtained from the S/C-CA1 pathway in +/+ (top) and Ws/Ws mutant (bottom) rats. Calibration bars; horizontal, $10 \mathrm{~ms}$; vertical, $1 \mathrm{mV}$. (Ab) Mean values of PPF in $+/+$ (open bar, $n=10$ ) and mutant (solid bar, $n=12$ ) rats at each interstimulus interval. (Ba) Averaged waveforms of 10 traces evoked by paired pulses $(\mathbf{\Lambda})$ obtained from MF-CA31 pathway in +/+ (top) and Ws/Ws mutant (bottom) rats. Calibration bars; horizontal, $10 \mathrm{~ms}$; vertical, $0.4 \mathrm{mV}$. (Bb) Mean values of PPF in $+/+$ (open bar, $n=11$ ) and mutant (solid bar, $n=15)$ rats at each interstimulus interval $(* *, P<0.01$, Bonferroni's test).

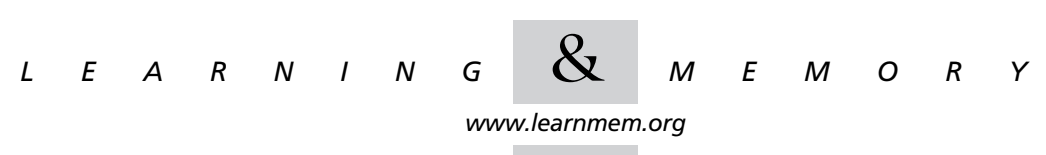


A $\underset{\mathrm{a}}{\mathrm{CA} 1}$

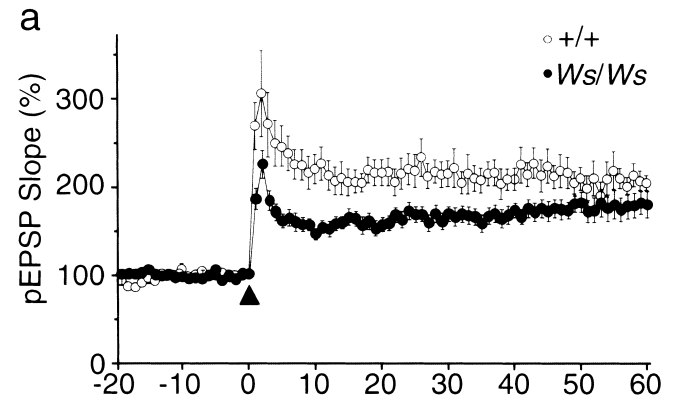

B CA3

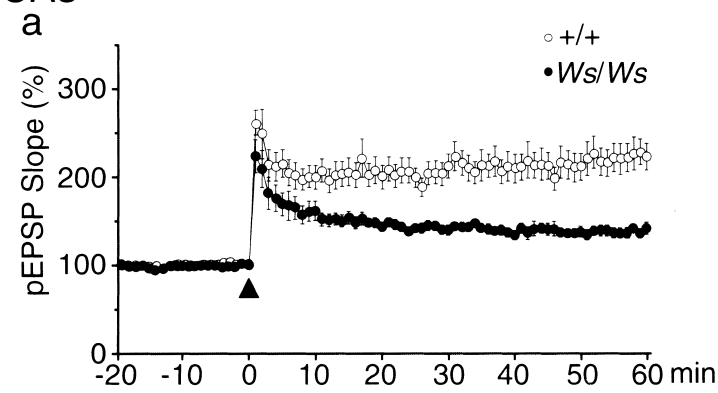

b

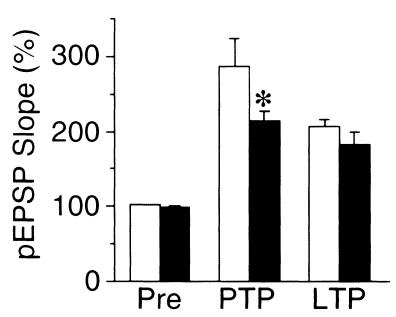

b

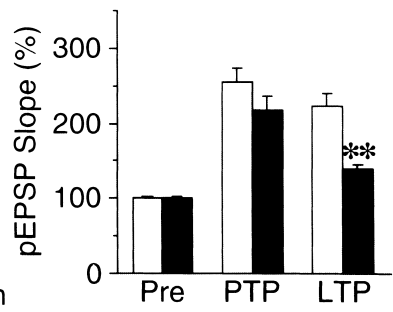

Figure 3 Tetanus-induced synaptic potentiation in CA1 and CA3. (Aa) Percent slopes of S/C-CA1 field potentials are plotted against time. After baseline responses were stable for at least $20 \mathrm{~min}$, tetanus stimulation $(100 \mathrm{~Hz}, 1 \mathrm{sec})$ was given at time $0 .(O),+/+$ control rats $(n=10)$ and $(\bullet)$, $W s / W s$ mutant rats $(n=12)$. (Ab) Summary of baseline (Pre), PTP, and LTP in S/C-CA1 pathway in $+/+$ (open bar, $n=10$ ) and $W s / W s$ mutant (solid bar, $n=12$ ) rats. Pre, PTP, and LTP are expressed as averages of the pEPSP slope 20-0 min before tetanus 1-2 $\mathrm{min}$, and 55-60 min after tetanus, respectively. $\left(^{*}\right) P<0.05$, Bonferroni's test. (Ba) Percent slopes of MF-CA3 field potentials are plotted against time. Tetanus stimulation was given at time $0 .(\bigcirc),+/+$ control rats $(n=11)$ and $(\bullet)$, Ws/Ws mutant rats $(n=15)$. (Bb) Summary of Pre, PTP, and LTP in MF-CA3 pathway in $+/+$ (open bar, $n=11$ ) and $W s / W s$ mutant (solid bar, $n=15)$ rats. $\left.{ }^{* *}\right), P<0.01$, Bonferroni's test.

compared with those in control rats. The data are summarized in Figure $3 \mathrm{Ab}$ and $\mathrm{Bb}$ in the forms of post-tetanic potentiation (PTP, mean pEPSP slope during the period 1-2 min after tetanus) and persistent LTP (55-60 min). There is an overall difference between the groups (for CA1, $\mathrm{F}_{1,80}=14.21, P<0.01$, two-way ANOVA, and for CA3 $\left.,_{1,96}=26.57, P<0.01\right)$. As for the S/C-CA1 pathway, Bonferroni's post-hoc test indicated that PTP $(207.7 \pm 12.5 \%)$ but not LTP $(180.6 \pm 15.9 \%)$ in mutant rats were significantly smaller than that in control rats (PTP, $287.0 \pm 36.4 \%, P<0.05$; LTP, $206.9 \pm 9.7 \%, P>0.05$ ). In the MF-CA3 pathway, the differences were significant in LTP $(139.5 \pm 5.2$ vs. $224.1 \pm 16.0 \%, P<0.01)$, but not in PTP $(217.7 \pm 18.7$ vs. $255.5 \pm 18.1 \%, P>0.05)$.

\section{PPF after Tetanic Stimulation}

Sixty minutes after the induction of LTP, PPF was again examined at the same stimulus intensity and interstimulus intervals. Examples of the averaged waveforms of control and mutant rats in both CA1 (Fig. 4Aa) and CA3 (Fig. 4Ba) were recorded from the same slice preparation as those shown in Figure 2Aa (CA1) and Ba (CA3) corresponding to the respective traces.
Although the mean value of CA1 PPF in control rats seemed to decrease after tetanic stimulation ( $40 \mathrm{~ms}$, before tetanus, 210. 2 $\pm 16.2 \%$ vs. after tetanus, $172.5 \pm$ $16.8 \%$; $80 \mathrm{~ms}, 192.8 \pm 15.8$ vs. $174.2 \pm 25.4 \%$ ), there was no significant difference. In mutant rats, the mean CA1 PPF also showed no significant changes after tetanic stimulation ( $40 \mathrm{~ms}$, before tetanus, $179.7 \pm 14.1 \%$ vs. after tetanus, $166.4 \pm 11.6 \%, P>0.05 ; 80 \mathrm{~ms}$, $187.6 \pm 15.4$ vs. $170.0 \pm 11.5 \%$, $P>0.05)$. Thus, there were no differences in the mean CA1 PPF between controls and mutants (Fig. $4 \mathrm{Ab})$ as observed before tetanus (Fig. 2Ab).

In the MF-CA3 pathway, the averages of PPF after tetanic stimulation in control rats were significantly smaller than those before tetanus ( $40 \mathrm{~ms}$, before tetanus, $179.2 \pm 9.7 \%$ vs. after tetanus, $121.8 \pm 5.4 \%, P<0.01 ; 80 \mathrm{~ms}$, $140.8 \pm 6.5 \%$ vs. $119.4 \pm 2.0 \%$, $P<0.01)$. In mutant rats, the mean CA3 PPF showed no significant changes after tetanic stimulation (40 ms, before tetanus, $141.7 \pm$ $9.0 \%$ vs. after tetanus, $136.5 \pm 5.3 \%, P>0.05 ; 80 \mathrm{~ms}, 112.1$ $\pm 4.3 \%$ vs. $120.1 \pm 5.4 \%, P>0.05$ ). Thus, in CA3, the difference in PPF between control and mutants that was significant before tetanus (Fig. 2Bb), disappeared when examined after LTP (Fig. 4Bb).

\section{Correlation between PPF, PTP, and LTP in CA1}

To further characterize the interrelations of synaptic potentiations in control and mutant rats, the correlation analysis was performed by use of the initial PPF at an 80-ms interstimulus interval, PTP and LTP of each slice. In the S/C-CA1 pathway, there was a positive correlation between PPF and PTP (Fig. 5A, $\bigcirc$ and a broken line, $r=0.78, P<0.01, n=10$, $y=1.79 x-57.2)$ in control rats, whereas CA1 PPF did not correlate with PTP in mutant rats (Fig. 5A, and solid line, $r=0.37, P>0.05, n=12, y=0.29 x+152.4)$. In contrast to the positive correlation between PPF and PTP, there was no significant correlation between PPF and LTP (Fig. 5B, $\bigcirc$, $r=0.27, P>0.05, n=10, y=0.14 x+179.7)$ and between PTP and LTP (Fig. 5C, $\bigcirc, r=0.50, P>0.05, n=10$, $y=0.12 x+173.8)$ in control rats, or in mutant rats (PPF vs. LTP, Fig. 5B, $, r=0.43, P>0.05, n=12, y=0.37 x+$

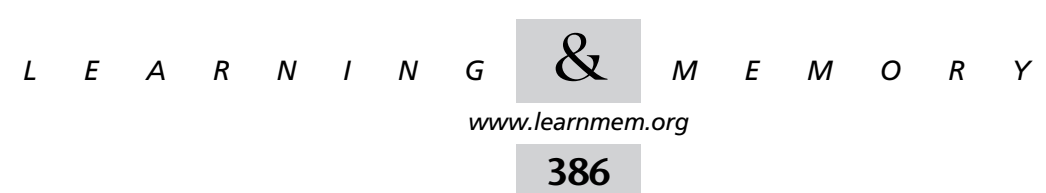


A CA1

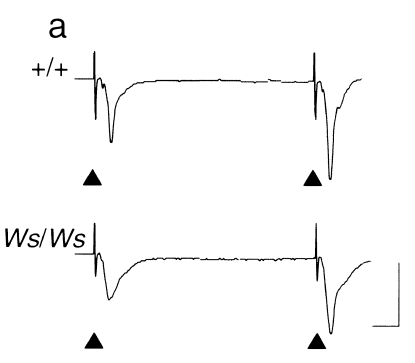

b

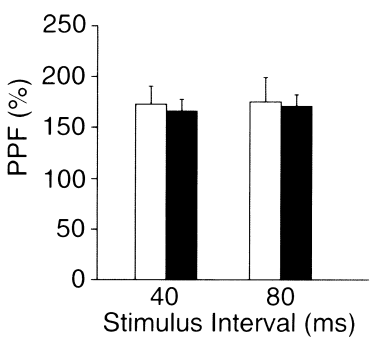

B $\mathrm{CA} 3$
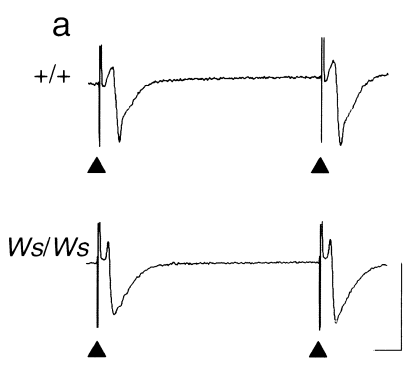

b

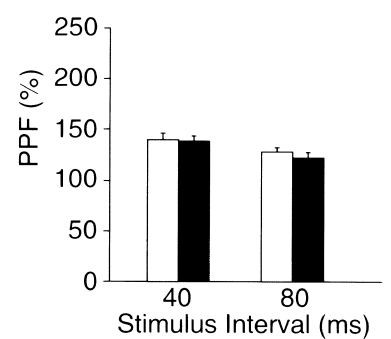

Figure 4 PPF Recorded from CA1 and CA3 after establishment of LTP. (Aa) Averaged waveforms of 10 traces evoked by paired pulses $(\mathbf{\Lambda})$ at an $80-\mathrm{ms}$ interstimulus interval obtained from the S/C-CA1 pathway in +/+ (top) and Ws/Ws mutant (bottom) rats. Stimulus intensity was the same as that before tetanus. Calibration bars; horizontal, $10 \mathrm{~ms}$; vertical, $1 \mathrm{mV}$. (Ab) Mean values of PPF in $+/+$ (open bar, $n=10$ ) and mutant (solid bar, $n=12$ ) rats at each interstimulus interval. (Ba) Averaged waveforms of 10 traces evoked by paired pulses $(\boldsymbol{\Lambda})$ obtained from MF-CA3 pathway in $+/+($ top) and $W s / W s$ mutant (bottom) rats. Stimulus intensity was the same as that before tetanus. Calibration bars; horizontal, $10 \mathrm{~ms}$; vertical, $0.4 \mathrm{mV}$. (Bb) Mean values of PPF in $+/+$ (open bar, $n=11$ ) and mutant (solid bar, $n=15$ ) rats at each interstimulus interval.

111.3; PTP vs. LTP, Fig. 5C, $\bigcirc, r=0.01, P>0.05, n=12$, $y=-0.02 x+183.7)$.

Correlation Between PPF, PTP, and LTP in CA3

In the area CA3, PTP positively correlated with the initial PPF in control rats (Fig. 6A, $\bigcirc, r=0.89, P<0.01, n=11$, $y=2.47 x-92.0$ ) as in area CA1 (Fig. 5A). Furthermore, there was also positive correlation between PPF and LTP (Fig. 6B, $\bigcirc, r=0.80, P<0.01, n=11, y=1.95 x-50.6$ ) and between PTP and LTP (Fig. 6C, $\bigcirc, r=0.72, P<0.05, n=11$, $y=0.63 x+63.0)$. It is possible that not only MF but also the associational/commissural pathway, which is another excitatory input to CA3 pyramidal cells showing the NMDA-dependent LTP, may also be stimulated in the present study. However, it was clearly demonstrated that PPF and PTP correlated positively with LTP in CA3 (Fig. 6B,C), whereas there was no correlation between them recorded from area CA1 in control rats (Fig. 5). In addition, the coaxial stimulating electrode (tip diameter, $0.3 \mathrm{~mm}$ ) was placed just on the granule cell layer. Therefore, taken together, the contamination of the associational/commissural pathway seemed to be only the minimum in the present study.

In mutant rats, PTP positively correlated with the initial PPF (Fig. 6A, O, $r=0.75 P<0.01, n=15, \quad y=3.7 x$ - 200.2), as in control rats (Fig. 6A, $\bigcirc$ ). However, the positive correlation between PPF and LTP (Fig. 6B,,$r=0.15$, $P>0.05, n=15, y=0.21 x+116.5)$ and between PTP and LTP (Fig. 6C, $, r=0.01, P>0.05, n=15, y=-0.03 x+$

138.8) was abolished in $c$-kit mutant rats.

\section{Correlation between PPF before and after LTP}

It has been shown that PPF changed specifically in association with LTP in the S/C-CA1 pathway, when the PPF is measured before and after LTP (Schulz et al. 1994). Thus, the correlation between the initial PPF and changes in PPF after the establishment of LTP was investigated. In Figure 7A, each value of PPF before tetanic stimulation at an 80-ms interstimulus interval (initial PPF) was plotted against changes in PPF after LTP (calculated as PPF at test stimula-
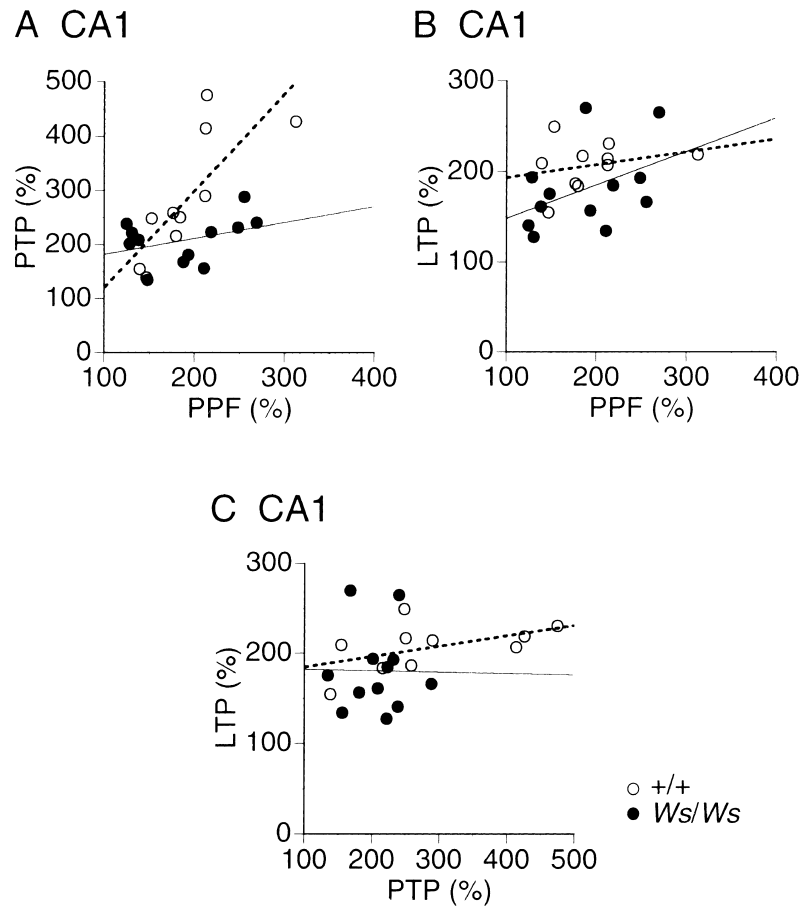

Figure 5 Correlation between the Initial PPF and PTP, PPF and LTP, and PTP and LTP in the S/C-CA1 pathway. S/C-CA1 PTP $(A)$ $\operatorname{LTP}(B)$, and LTP $(C)$ were plotted against the initial PPF at an 80-ms interstimulus interval and PTP of each slice, respectively, in $+/+$ $(n=10)$ and mutant $(n=12)$ rats. (A) Positive correlation between PPF and PTP in $+/+$ rats $(O$ and broken line, $r=0.78, P<0.01)$, whereas there is no correlation in mutants and solid line, $r=0.37, P>0.05)$. (B) No correlation between PPF and LTP in $+/+$ ( $\bigcirc$ and broken line, $r=0.27, P>0.05)$, and mutant $(\bigcirc$ and solid line, $r=0.43, P>0.05)$ rats. $(C)$ No correlation between PTP and LTP in $+/+(O$ and broken line, $r=0.50, P>0.05)$, and mutant and solid line, $r=0.01, P>0.05)$ rats.

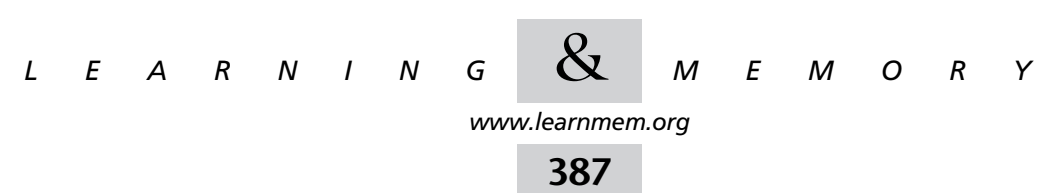


A CA3

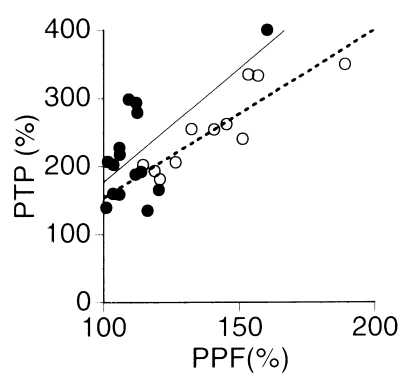

C CA3

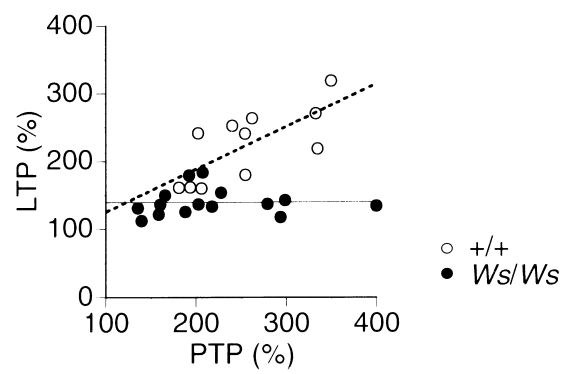

Figure 6 Correlation between the Initial PPF and PTP, PPF and LTP, and PTP and LTP in the MF-CA3 pathway. MF-CA3 PTP $(A)$ $\operatorname{LTP}(B)$, and LTP $(C)$ were plotted against the initial PPF at an 80-ms interstimulus interval and PTP of each slice, respectively, in $+/+(n=11)$ and mutant $(n=15)$ rats. (A) Positive correlation between PPF and PTP in $+/+(\bigcirc$ and broken line, $r=0.89, P<0.01)$ and mutant $(-$ and solid line, $r=0.75, P<0.01)$ rats. (B) Positive correlation between PPF and LTP in $+/+$ rats $(O$ and broken line, $r=0.80, P<0.01)$, whereas there was no correlation in mutants ( and solid line, $r=0.15 P>0.05$ ). (C) Positive correlation between PTP and LTP in $+/+$ rats $(O$ and broken line, $r=0.72, P<0.05)$, whereas there was no correlation in mutants $(-$ and solid line, $r=0.01, P>0.05)$.

tion intensity measured after LTP minus initial PPF). In +/+ control rats, the changes in CA1 PPF with LTP showed an inverse relationship with the initial PPF (Fig. 7A, $\bigcirc$, $r=0.63, P<0.05, n=10, y=-0.37 x+41.7)$, which was consistent with the findings in the previous studies (Schulz et al. 1994). In Ws/Ws mutant rats, the inverse relationship between them was also observed as in control rats (Fig. 7A, and a solid line, $r=0.66, P<0.05, n=12, y=-0.47 x+$ 69.7).

In the area CA3, the changes in PPF after LTP in control rats correlated inversely with initial PPF (Fig. 7B, $\bigcirc$ and broken line, $r=0.95, P<0.01, n=11, y=-0.96 x+113.5)$ as in area CA1. This change in PPF in association with LTP is thought to be consistent with a predominant involvement of presynaptic components in the mechanisms of formation of MF-CA3 LTP. In contrast to CA1, there was no significant correlation between the initial PPF and changes in PPF after LTP in mutant rats (Fig. 7B, $\bigcirc$ and solid line, $r=0.40, P>$ $0.05, n=15, y=-0.62 x+77.3)$.

\section{DISCUSSION}

The aim of this study was to examine the involvement of the c-kit signaling in learning and memory and synaptic potentiation by use of $c$-kit mutant rats, in which the activity of c-kit receptor tyrosine kinase is very low (Tei et al. 1994). The previous study using heterozygous $S l / S l^{d}$ mutant mice, which are characterized by the lack of the membranebound form of SCF, but not the soluble-type SCF (Flanagen et al. 1991), showed a deficit in spatial learning and memory, reduction of baseline synaptic transmission but normal LTP in the MF-CA3 pathway (Motro et al. 1996). In the present study, the $c$-kit (Ws/Ws) mutant rats also demonstrated an impairment of spatial learning. However, in contrast to $S l / S l^{d}$ mutant mice, the synaptic potentiation such as LTP and PPF and the positive correlation between PPF and LTP in the MF-CA3 pathway were deteriorated in c-kit mutant rats. Although there is a difference in species (mice vs. rats), these findings give further evidence for an importance of $c$-kit/SCF signaling in learning and memory and hippocampal synaptic potentiation. Furthermore, our findings suggest an importance of the soluble-type SCF in hippocampal synaptic potentiation. The normal LTP observed in $S l / S l^{d}$ mice (Motro et al. 1996) may be due to the presence of soluble-type SCF and intact $c$-kit receptors.

\section{Impairment of Synaptic Potentiation in c-kit Mutants}

The present study demonstrated (1) that the reduction of the initial PPF was evident in CA3 but not in CA1 regions (Fig. $2 \mathrm{Ab}, \mathrm{Bb}$ ), and (2) that the LTP in the MF-CA3 pathway, but not in the S/C-CA1 pathway, was significantly smaller than that of $+/+$ control rats (Fig. 3). Therefore, the impairment of $c$-kit mutant rats seemed to be more severe in the $\mathrm{MF}-\mathrm{CA} 3$ pathway than in the S/C-CA1 pathway. In the pre-
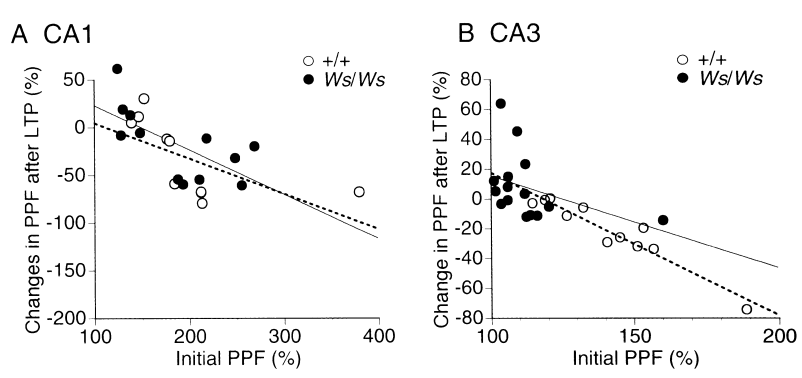

Figure 7 Correlation between the initial PPF and changes in PPF after the establishment of LTP. Changes in PPF after LTP were plotted against the initial PPF of each slice in S/C-CA1 $(A)$ and MF-CA3 (B) pathways. Interstimulus interval of PPFs was $80 \mathrm{~ms}$. (A) Negative correlation between the initial PPF and changes in PPF after LTP in the S/C-CA1 pathway in $+/+(\mathrm{O}$ and broken line, $r=0.63, P<0.05, n=10)$ and mutant $(-$ and solid line, $r=0.66$, $P<0.05, n=12)$ rats. $(B)$ Negative correlation between the initial PPF and changes in PPF after LTP in the MF-CA3 pathway in $+/+$ rats $(\bigcirc$ and broken line, $r=0.95, P<0.01, n=11)$, whereas there was no correlation in mutants $($ and solid line, $r=0.40, P>0.05$, $n=15)$.

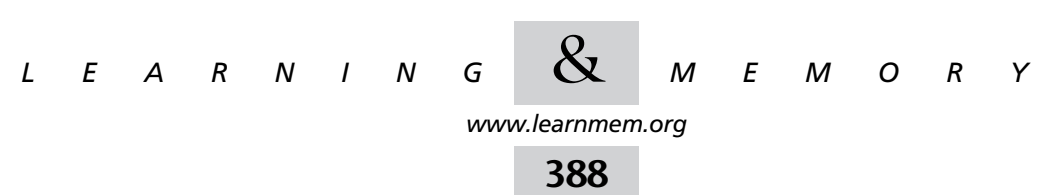


sent study, we analyzed not only the averages of PPF, PTP, and LTP but also the correlation among them, which were shown to be useful to detect the differences in synaptic potentiation between control and mutant rats.

The induction and expression mechanisms of LTP in the MF-CA3 pathway are shown to be primarily of presynaptic origin (Zalutsky and Nicoll 1990; Castillo et al. 1994; Nicoll and Malenka 1995; Son and Carpenter 1996a). The PPF, as well as the PTP, is also thought to be a presynaptically mediated phenomenon that is associated with an increase in transmitter release probability and mean quantal content resulting from a transient increase in presynaptic $\mathrm{Ca}^{2+}$ triggered by the first stimulation (Kuhnt and Voronin 1994; Schulz et al. 1994). Thus, it is likely that in the MFCA3 pathway, PPF, LTP, and PTP share common mechanisms. In fact, there was positive correlation between PPF and LTP, between PPF and PTP, and between PTP and LTP in the CA3 region of control rats (Fig. 6), as observed previously (Son and Carpenter 1996a). In the S/C-CA1 pathway, there was also the positive correlation between PPF and PTP, but no correlation between PPF and LTP or between PTP and LTP in control rats (Fig. 5). This may be reasonable because the mechanism of CA1 LTP is considered to be mainly postsynaptic in origin, whereas both PPF and PTP are presynaptic.

The positive correlation between PPF and PTP in CA1, which was observed in control rats, was abolished in $c$-kit mutant rats (Fig. 5A). This might be due to the reduction of the size of PTP (Fig. 3Ab) in mutant rats. In contrast, the positive correlation between PPF and PTP in CA3 was not abolished in mutant rats (Fig. 6A). In the MF-CA3 pathway, the amplitude of PPF in mutant rats was smaller than that in controls (Fig. 2Bb), but the size of PTP was not affected (Fig. 3Bb). Therefore, it is possible that the mechanisms that determine the amplitude of PTP may be different between CA1 and CA3. On the other hand, the positive correlation between PPF and LTP and between PTP and LTP in CA3, which was observed in control rats, was abolished in mutant rats (Fig. 6B,C). These findings suggest that c-kit mutant rats have an impairment of the presynaptically mediated synaptic potentiation, and thus c-kit may play a significant role in synaptic potentiation in the MF-CA3 pathway. This finding is consistent with our recent observation that the induction of the tetanus-induced LTP in the MF-CA3 pathway of mouse slice preparations is completely blocked by preincubation of slices with anti-c-kit antibody for $2 \mathrm{hr}$ (Katafuchi et al. 1998).

\section{Negative Correlation between PPFs before and after LTP}

There are controversial reports as to whether or not the tetanus-induced LTP can modulate the amplitude of PPF in the S/C-CA1 pathway. The attenuation (Wang and Kelly 1997), no change (Manabe et al. 1993), and both increase and decrease (Schulz et al. 1994) in PPF magnitude after LTP have been reported. In spite of the diversity of the changes in PPF amplitude, Schulz et al. (1994) have shown that a larger initial PPF is associated with a decrease in PPF when measured after LTP, whereas a smaller initial PPF is associated with an increase in PPF after LTP (negative correlation). This may be explained as follows: the presynaptic terminals with the low initial probability (Pre-low) must show the large PPF, whereas those with high probability (Pre-high) must show the small PPF. When LTP induces an increase in the probability of neurotransmitter release at the Pre-low, the originally large PPF would become small. On the other hand, when LTP increases new release sites having a low probability at the Pre-high, the small PPF would become large, thereby producing the negative correlation between the initial PPF and changes in PPF after LTP. Thus, the LTP-induced negative correlation may indicate, at least in part, an involvement of presynaptic locus in the expression mechanism of CA1 LTP, although others have shown that the attenuation of PPF after LTP may be mediated by postsynaptic mechanisms including postsynaptic $\mathrm{Ca}^{2+} / \mathrm{CaM}$ signaling pathways (Wang and Kelly 1997). In the present study, when the changes in PPF after LTP were plotted against the initial PPF, there was a negative correlation between them in the S/C-CA1 pathway (Fig. 7A) as reported by Schulz et al. (1994). Furthermore, we found that there was also the negative correlation between them in the MFCA3 pathway of control rats (Fig. 7B). This is consistent with the view that both the induction and expression mechanisms of LTP may be of a presynaptic origin in the MF-CA3 pathway (Zalutsky and Nicoll 1990; Castillo et al. 1994; Nicoll and Malenka 1995; Son and Carpenter 1996a).

The present study demonstrated that the negative correlation between the initial PPF and the changes in PPF after LTP in the MF-CA3 pathway was abolished in c-kit mutant rats (Fig. 7B), but was preserved in the S/C-CA1 pathway in mutant rats (Fig. 7A). This finding again suggests that $c$-kit/ SCF signaling may play a significant role in presynaptically mediated potentiation. It has been demonstrated that in the MF-CA3 pathway $c$-kit receptor mRNA is mainly expressed in CA3 pyramidal cells but very low in density in the granule cells of the dentate gyrus in normal rats (Hirota et al. 1992). In mice there were no expressions of $c$-kit mRNA in granule cells (Motro et al. 1991). These findings, taken together, suggest that the $c$-kit/SCF signal transduction at the postsynaptic site (CA3 pyramidal cells) produces a retrograde signal(s) that diffuses to the presynaptic membranes (MF terminals) and affects transmitter release processes.

\section{Possible Mechanisms of Deficit in Synaptic Potentiation in c-kit Mutants}

The mechanisms of the $c-k i t / S C F$ signaling in neuronal cells have not yet been determined. However, it has been shown that SCF activates phospholipase D (PLD) through a phos-

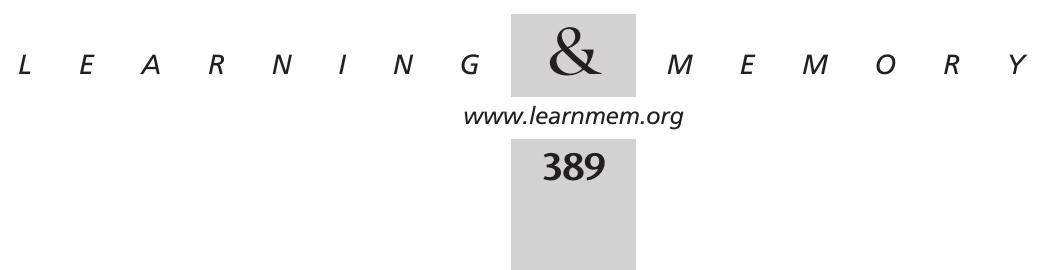


phatidylinositol 3 '-kinase-dependent pathway in cultured porcine aortic endothelial cells transfected with $c$-kit receptors, leading to the production of phosphatidic acid. Phosphatidic acid is then metabolized to yield diacylgycerol (DAG), which serves as an activator of protein kinase $\mathrm{C}$ (PKC), and as a precursor to arachidonic acid (AA) by the action of DAG lipase and monoacylglycerol lipase. In addition, AA is released by SCF through an alternative route that involves an activation of phospholipase $\mathrm{A}_{2}\left(\mathrm{PLA}_{2}\right)$ (Kozawa et al. 1997). Thus, one of the candidates that mediate the retrograde synaptic transmission triggered by SCF may be AA, which is shown to enhance depolarization-evoked glutamate release from hippocampal MF nerve endings in a $\mathrm{Ca}^{2+}$ - and presynaptic PKC-dependent way (Zhang et al. 1996). We have shown that the initial value of PPF negatively correlated with changes in PPF after the establishment of LTP in the MF-CA3 pathway by use of mouse slice preparations, as observed in control rats in the present study. Furthermore, bath application of mouse recombinant SCF for $30 \mathrm{~min}$ induced a similar negative correlation between the PPFs before and after the perfusion (Katafuchi et al. 1998). Recently we have observed that the SCF-induced negative correlation between the PPFs is abolished by the simultaneous application of PLA $\mathrm{P}_{2}$ inhibitor, quinacrine (T. Katafuchi, unpubl.).

AA has been shown to have synergistic action of DAG for PKC activation (Shinomura et al. 1991), and induce PKCdependent facilitation of glutamate release from MF nerve endings (Zhang et al. 1996). Activation of PKC is not sufficient but necessary for induction of LTP in the MF-CA3 pathway (Son and Carpenter 1996b). Thus, the impairment of synaptic potentiation in c-kit mutant rats may involve a down-regulation of PKC activity in the presynaptic terminals. Furthermore, the suppressive action of subtype 2 of the metabotropic glutamate receptor (mGluR2) on synaptic transmission in the MF-CA3 pathway (Kamiya et al. 1996), may be enhanced in c-kit mutant rats, as PKC reduces the inhibitory effect produced by subtype 2 of mGluR (Swartz et al. 1993).

Several other mechanisms may be considered as the cause of the impairment of synaptic potentiation in $c$-kit mutant rats. First, the cyclic AMP (cAMP)-protein kinase A (PKA) cascade is also important presynaptically for LTP in the MF-CA3 pathway (Huang et al. 1994; Weisskopf et al. 1994). However, it has been shown that the genetic ablation of either catalytic (C) $\beta_{1}$ or regulatory (R) I $\beta$ subunit of PKA has no effect on PPF or spatial learning despite the elimination of the MF-CA3 LTP (Huang et al. 1995). Second, the significant reduction of the histamine content of the whole brain in c-kit mutant rats due to the depletion of mast cells (Sugimoto et al. 1995) may contribute to the impairment of synaptic potentiation. However, it is unlikely that the MF-CA3 LTP, which is known to be NMDA independent, is affected by histamine because it facilitates the in- duction of LTP, most likely by acting directly on the NMDA receptor (Brown et al. 1995). In addition, there was no significant difference in the histamine content of the hippocampus between $c$-kit mutant and control rats, possibly because of the non-mast cell histamine pools including histaminergic neurons (Sugimoto et al. 1995). Finally, it has been shown that $c$-kit receptor is also expressed in microglia and that SCF potentiates microglial expression of mRNA for brain-derived neurotrophic factor (BDNF) (Zhang and Fedoroff 1998). Thus, it is possible that there is an impairment of BDNF production in c-kit mutant rats, thereby resulting in a deficit in the synaptic potentiation and learning and memory. Further studies will be needed to obtain direct evidence for the mechanisms of the impairment in $c$-kit mutant rats.

\section{MATERIALS AND METHODS}

\section{Rats}

Adult (8-12 wk old), male $W s / W s$ mutant and control $+/+$ rats weighing $200-300 \mathrm{~g}$ were used. They were originally bred in the Department of Pathology, Osaka University, and were transferred to the colony in the Kyushu University at least $2 \mathrm{wk}$ before the present work started. They were housed at $22 \pm 2^{\circ} \mathrm{C}$ with artificial light illumination from 0700 to 1900 hours. Food and water were provided ad libitum. There was no obvious abnormality in general behavior in both groups of rats. Different animals were used for behavioral and electrophysiological studies.

The origin and breeding procedure of $\mathrm{Ws} / \mathrm{Ws}$ rats have been described previously (Niwa et al. 1991). The c-kit mutant rats of $W s / W s$ genotype have black eyes and white hair because of the lack of melanocytes except for the retina. The Ws/Ws rats showed hypoplastic anemia at birth, but it tended to ameliorate $10 \mathrm{wk}$ after birth. In addition, mast cells are depleted in the mutant rats as in the $W\left(W / W^{v}\right)$ and $S l\left(S l / S l^{d}\right)$ mutant mice (Niwa et al. 1991). The c-kit cDNA of Ws/Ws mutant allele was found to have a deletion of 12 bases, which was shown to be a result of the deletion of the genomic DNA. Four amino acids encoded by the deleted 12 bases are located at two amino acids downstream from the tyrosine autophosphorylation site in the $c$-kit kinase and are also conserved in mouse and human $c$-kit kinases. The Ws/Ws rat is the first characterized mutant of the $c$-kit gene in an animal species other the mouse (Tsujimura et al. 1991). An in vitro immune complex kinase assay indicated that the $c$-kit kinase activity was apparently lower in cultured mast cells of $W s / W s$ rats than those of $+/+$ control rats (Tei et al. 1994).

\section{Morris Water Maze Studies}

To measure the ability of spatial memory and learning of rats, we compared the performance of $W s / W s$ mutant $(n=6)$ and $+/+$ control rats $(n=6)$ in the hidden-platform version of the Morris water maze. Rats were brought to the testing room at least $5 \mathrm{~d}$ before behavioral testing. The apparatus was a black plastic circular pool (diameter, $150 \mathrm{~cm}$; wall height, $76 \mathrm{~cm}$ ) containing water at 22-23 ${ }^{\circ} \mathrm{C}$. The pool was surrounded by a gray curtain wall, on which three rectangular, triangular, and circular drawings that were brightly illuminated were placed and served as the spatial cues. A circular, transparent plastic platform (diameter, $12 \mathrm{~cm}$ ) was placed in one quadrant of the pool $2 \mathrm{~cm}$ below the surface of the water. The rats

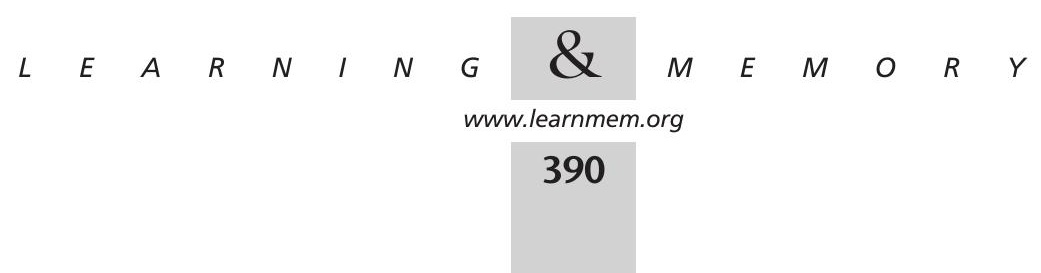


were released from one of four randomly chosen starting points in the circular pool for $60 \mathrm{sec}$ to search for the hidden escape platform. They were allowed to rest for $30 \mathrm{sec}$ on the platform after they found it. If the rats could not find the platform within $60 \mathrm{sec}$, the experimenter placed the animal on the platform for $30 \mathrm{sec}$. Rats were then placed for $60 \mathrm{sec}$ in a waiting cage for the next trial and were dried under a heating lamp. The rats received four trials (one block) twice (1000-1200 hours and 1500-1700 hours) a day for two consecutive days. There were no rats that did not show motivation for swimming (floating behavior) both in mutant and control groups. The rats were tracked by an infrared-sensitive camera connected to a maze analysis unit (Toyo Industrial Co., MAZER MZ-40). A probe test was performed after the end of the fourth block. In this test, the rats were allowed to search for $60 \mathrm{sec}$ with no platform present. The duration of cumulative time that they spent in each of the quadrants and the numbers crossing the trained platform position were measured in the probe test.

\section{Electrophysiology}

Under anesthesia with ether, rats were killed by a blow to the neck and decapitated. The brain was quickly removed. The hippocampal slices (400- $\mu \mathrm{m}$ thick) were made perpendicular to the septotemporal axis for the study of the S/C-CA1 pathway or transverse to the axis for the study of the MF-CA3 pathway. They were incubated in Krebs-Ringer solution bubbled with $95 \% \mathrm{O}_{2}$ and $5 \% \mathrm{CO}_{2}$ at $32-34^{\circ} \mathrm{C}$ and at $\mathrm{pH} 7.4$. After $2 \mathrm{hr}$ pre-incubation, slices were transferred to a recording chamber, which was perfused with Krebs-Ringer solution at a constant rate of $\sim 2.5 \mathrm{~mL} / \mathrm{min}$. The Krebs-Ringer solution contained (in millimolars) the following: $124 \mathrm{NaCl}, 4 \mathrm{KCl}, 1.3$ $\mathrm{MgSO}_{4}, 1.23 \mathrm{NaH}_{2} \mathrm{PO}_{4}, 26 \mathrm{NaHCO}_{3}, 2.4 \mathrm{CaCl}_{2}$, and 10 glucose. Extracellular recording of population pEPSP was made from the stratum radiatum in the area CA1 or from the stratum lucidum in the area $\mathrm{CA} 3$ by a glass microelectrode filled with Krebs-Ringer solution (tip diameter, 15-25 $\mu \mathrm{m}$; DC resistance, 3-5 $\Omega$ ). Orthodromic stimuli were delivered through a coaxial bipolar electrode (diameter, $0.3 \mathrm{~mm}$ ) that was placed in the stratum radiatum in the CA3 region to stimulate the S/C-CA1 pathway or in the granule cell layer of the dentate gyrus to stimulate the MF-CA3 pathway. The test-stimulus intensity of $50 \mu$ square pulses was adjusted to give a pEPSP amplitude of $0.2-0.7 \mathrm{mV}$ at $0.03 \mathrm{~Hz}$ (finally, $0.15-0.65 \mathrm{~mA}$ ). After having confirmed that the amplitude of pEPSP was stable for at least $10 \mathrm{~min}$, PPF was measured with interstimulus intervals of 40 and $80 \mathrm{~ms}$. Paired-pulse stimuli were applied 10 times at $0.1 \mathrm{~Hz}$ for each interval. Stable pEPSPs, the amplitude of which was confirmed to be the same as that before PPF, were again obtained for 20 min without changing stimulus intensity. Then tetanic stimulation was delivered and data were collected for another $60 \mathrm{~min}$. To induce LTP, a train of $100 \mathrm{~Hz}$ for $1 \mathrm{sec}$ was delivered at the same stimulus intensity used for the test stimulus. PPF was re-measured $60 \mathrm{~min}$ after the end of the tetanic stimulation with the same interstimulus intervals.

Responses were acquired, digitized, and stored by a Macintosh computer interfaced with MacLab (AD Instruments) at $20 \mathrm{kHz}$ for $64 \mathrm{~ms}$ or at $10 \mathrm{kHz}$ for $128 \mathrm{~ms}$, beginning $4 \mathrm{~ms}$ prior to the stimulation. For the analysis of PPF, the 10 traces at each interstimulus interval were averaged and the slope of the middle twothirds of the rising phase of pEPSP (1.2-1.5 ms for S/C-CA1 and $0.8-1.0 \mathrm{~ms}$ for MF-CA3 pathways) was measured in $\mathrm{mV} / \mathrm{ms}$. To avoid bias, the same time points on the initial slope of pEPSP were analyzed throughout the experiment. PPF was calculated as a percent ratio of the slope of the second pEPSP to the first. For LTP analysis, the initial slope of the pEPSP at each time point was expressed as a percentage of control values (averages before tetanic stimulation). After a tetanic stimulation, PTP was followed by a short-term potentiation (STP), which decayed within $\sim 20 \mathrm{~min}$, then LTP, a more persistent and significant enhancement in the synaptic transmission, lasted for hours (Bliss and Collingridge 1993). To analyze data of individual sets on synaptic potentiation, the mean percentages of the rising slope of the pEPSPs of each animal recorded from 1 to $2 \mathrm{~min}$ and from 55 to $60 \mathrm{~min}$ after tetanus were used as PTP and LTP, respectively. The averages of the pEPSP slopes recorded from 10 to $5 \mathrm{~min}$ before tetanus were served as the pre-tetanic stimulation baseline.

\section{Statistics}

The data were expressed as mean \pm S.E.M. The statistical analysis for the differences in the parameters of a Morris water maze task such as escape latency and search time between $c$-kit mutant and $+/+$ rats was performed by two-way ANOVA. When a significant overall $F$ score was obtained, the difference between groups at each block was analyzed by Bonferroni's modified $t$-test as a posthoc test. The differences in PPF and synaptic potentiation after tetanus were also examined by Bonferroni's modified $t$-test. A linear regression test was used for examining the correlation between two parameters among the initial PPF, PPF after the tetanic stimulation, PTP, and LTP. $P<0.05$ was considered to be statistically significant.

\section{ACKNOWLEDGMENTS}

This work was supported by a Grant-in Aid for Scientific Research [(B) 10557008 and 12470011 to T.K.] from the Ministry of Education, Science, and Culture, and the Special Coordination Funds for the Science and Technology from Science and Technology Agency (STA) of Japan.

The publication costs of this article were defrayed in part by payment of page charges. This article must therefore be hereby marked "advertisement" in accordance with 18 USC section 1734 solely to indicate this fact.

\section{REFERENCES}

Adachi, S., Ebi, Y., Nishikawa, S., Hayashi, S., Yamazaki, M., Kasugai, T., Yamamura, T., Nomura, S., and Kitamura, Y. 1992. Necessity of extracellular domain of $\mathrm{W}$ (c-kit) receptors for attachment of murine cultured mast cells to fibroblasts. Blood 79: 650-656.

Bliss, T.V.P. and Collingridge, G.L. 1993. A synaptic model of memory: Long-term potentiation in the hippocampus. Nature 361: 31-39.

Brown, R.E., Fedorov, N.B., Haas, H.L., and Reymann, K.G. 1995. Histaminergic modulation of synaptic plasticity in area CA1 of rat hippocampal slices. Neuropharmacology 34: 181-190.

Castillo, P.E., Weisskopf, M.G., and Nicoll, R.A. 1994. The role of $\mathrm{Ca}^{2+}$ channels in hippocampal mossy fiber synaptic transmission and long-term potentiation. Neuron 12: 261-269.

Chabot, B., Stephenson, D.A., Champan, V.M., Besmer, P., and Bernstein, A. 1988. The proto-oncogene $c$-kit encoding a transmembrane tyrosine kinase receptor maps to the mouse $W$ locus. Nature 335: 88-89.

Flanagen, J.G., Chan, D.C., and Leder, P. 1991. Transmembrane form of the kit ligand growth factor is determined by alternative splicing and is missing in the $S l^{d}$ mutant. Cell 64: 1025-1035.

Hirata, T., Morii, E., Morimoto, M., Kasugai, T., Tsujimura, T., Hirota, S., Kanakura, Y., Nomura, S., and Kitamura, T. 1993. Stem cell factor induces outgrowth of $c$-kit-positive neurites and supports the survival of $c$-kit-positive neurons in dorsal root ganglia of mouse embryos. Development 119: 49-56.

Hirota, S., Ito, A., Morii, E., Wanaka, A., Tohyama, M., Kitamura, Y., and

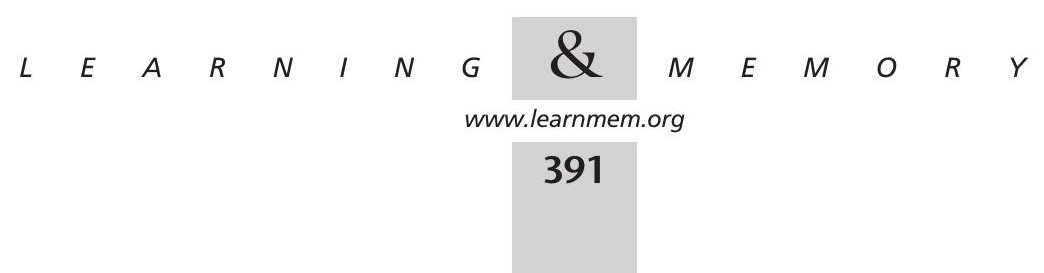


Nomura, S. 1992. Localization of mRNA for $c$-kit receptor and its ligand in the brain of adult rats: An analysis using in situ hybridization histochemistry. Mol. Brain Res. 15: 47-54.

Huang, E., Nocka, K., Beire, D.R., Chu, T., Buck, J., Lahm, H., Wellner, D., Leder, P., and Besmer, P. 1990. The hematopoietic growth factor KL is encoded by the $S l$ locus and is the ligand of the $c$-kit receptor, the gene product of the $W$ locus. Cell 63: 225-233.

Huang, Y-Y., Li, X-C., and Kandel, E.R. 1994. cAMP contributes to mossy fiber LTP by initiating both a covalently-mediately early phase and macromolecular synthesis-dependent late phase. Cell 79: 69-79.

Huang, Y-Y., Kandel, E.R., Varshavsky, L., Brandon, E.P., Qi, M., Idzerda, R.L., McKnight, G.S., and Bourtchouladze, R. 1995. A genetic test of the effects of mutations in PKA on mossy fiber LTP and its relation to spatial and contextual learning. Cell 83: 1211-1222.

Kamiya, H., Shinozaki, H., and Yamamoto, C. 1996. Activation of metabotropic glutamate receptor type $2 / 3$ suppresses transmission at rat hippocampal mossy fiber synapse. J. Physiol. 493: 447-455.

Katafuchi, T., Kondo, T., and Hori, T. 1998. Modulation of synaptic potentiation in mouse mossy fiber-CA3 pathway by a hematopoietic cytokine, stem cell factor (SCF). Soc. Neurosci. Abstr. 24: 445 (174.7)

Kozawa, O., Blume-Jensen, P., Heldin, C-H., and Ronnstrand, L. 1997. Involvement of phosphatidylinostiol 3'kinase in stem-cell-factor-induced phospholipase $\mathrm{D}$ activation and arachidonic acid release. Eur. J. Biochem. 248: 149-155.

Kuhnt, U. and Voronin, L. 1994. Interaction between paired-pulse facilitation and long-term potentiation in area CA1 of guinea pig hippocampal slices: application of quantal analysis. Neuroscience 62: 391-397.

Langtimm-Sedlak, C.J., Schroeder, B., Saskowski, J.L., Carnahan, J.F., and Sieber-Blum, M. 1996. Multiple actions of stem cell factor in neural crest cell differentiation in vitro. Dev. Biol. 174: 345-359.

Manabe, T., Wyllie, D.J.A., Perkel, D.J., and Nicoll, R.A. 1993. Modulation of synaptic transmission and long-term potentiation: Effect on paired-pulse facilitation and EPSC variance in the CA1 region of the hippocampus. J. Neurophysiol. 70: 1451-1459.

Matsui, Y., Zsebo, K.M., and Hogan, B.L. 1990. Embryonic expression of a haematopoietic growth factor encoded by the S1 locus and the ligand for c-kit. Nature 347: 667-669.

Motro, B., Van Der Kooy, D., Rossant, J., Reith, A., and Bernstein, A. 1991. Contiguous patterns of $c$-kit and steel expression: analysis of mutations at the $W$ and $S l$ loci. Development 113: 1207-1221.

Motro, B., Wojtowicz, J.M., Berstein, A., and van der Kooy, D. 1996. Steel mutant mice are deficient in hippocampal learning but not long-term potentiation. Proc. Natl. Acad. Sci. 93: 1808-1813.

Nicoll, R.A. and Malenka, R.C. 1995. Contrasting properties of two forms of long-term potentiation in the hippocampus. Nature 377: 115-118.

Niwa, Y., Kasugai, T., Ohno, K., Morimoto, M., Yamazaki, M., Dohmae, K., Nishimune, Y., Kondo, K., and Kitamura, Y. 1991. Anemia and mast cell depletion in mutant rats that are homozygous at "white spotting (Ws)" locus. Blood 78: 1936-1941.

Qui, F., Ray, P., Brown, K., Barker, P.E., Jhawer, S., Ruddle, F.H., and Besmer, P. 1988. Primary structure of $c$-kit: Relationship with the CSF-1/PDGF receptor kinase family - oncogenic activation of v-kit involves deletion of extracellular domain and C-terminus. EMBO J. 7: 1003-1011.

Schulz, P.E., Cook, E.P., and Johnston, D. 1994. Changes in paired-pulse facilitation suggest presynaptic involvement in long-term potentiation. J. Neurosci. 14: 5325-5337.

Shinomura, T., Asaoka, Y., Oka, M., Yoshida, K., and Nishizuka, Y. 1991 Synergistic action of diacylglycerol and unsaturated fatty acid for protein kinase C activation: Its possible implications. Proc. Natl. Acad. Sci. 88: 5149-5133.

Son, H. and Carpenter, D.O. 1996a. Interactions among paired-pulse facilitation and post-tetanic and long-term potentiation in the mossy fiber-CA3 pathway in rat hippocampus. Synapse 23: 302-311.

-1996b. Protein kinase C activation is necessary but not sufficient for induction of long-term potentiation at the synapse of mossy fiber-CA3 in the rat hippocampus. Neuroscience 72: 1-13.

Sugimoto, K., Maeyama, K., Alam, Md.K., Sakurai, E., Onoue, H., Kasugai, T., Kitamura, Y., and Watanabe, T. 1995. Brain histaminergic system in mast cell-deficient $(W s / W s)$ rats: Histamine content, histidine decarboxylase activity, and effects of $(S) \alpha$-fluoromethylhistidine. $J$. Neurochem. 65: 791-797.

Swartz, K.J., Merritt, A., Bean, B.P., and Lovinger, D.M. 1993. Protein kinase $\mathrm{C}$ modulates glutamate receptor inhibition of $\mathrm{Ca}^{+}$channels and synaptic transmission. Nature 361: 165-168.

Tei, H., Kasugai, T., Tsujimura, T., Adachi, S., Furitsu, T., Tohya, K., Kimura, M., Zsebo, K.M., Newlands, G.F.J., Miller, H.R.P., et al. 1994. Characterization of cultured mast cells derived from $W s / W s$ mast cell-deficient rats with a small deletion at tyrosine kinase domain of c-kit. Blood 83: 916-925.

Tsujimura, T., Hirota, S., Nomura, S., Niwa, Y., Yamazaki, M., Tono, T., Morii, E., Kim, H-M., Kondo, K., Nishimune, Y., and Kitamura, Y. 1991. Characterization of Ws mutant allele of rats: A 12-base deletion in tyrosine kinase domain of c-kit gene. Blood 78: 1942-1946.

Wang, J-H. and Kelly, P.T. 1997. Attenuation of paired-pulse facilitation associated with synaptic potentiation mediated by posysynaptic mechanisms. J. Neurophysiol. 78: 2707-2716.

Weisskopf, M.G., Castillo, P.E., Zalutsky, R.A., and Nicoll, R.A. 1994. Mediation of hippocampal mossy fiber long-term potentiation by cyclic AMP. Science 265: 1878-1882.

Williams, D.E., de Vries, P., Namen, A.E., Widmer, M.B., and Lyman, S.D. 1992. The Steel factor. Dev. Biol. 151: 368-376.

Wong, M-L. and Licinio, J. 1994. Localization of stem cell factor mRNA in adult rat hippocampus. Neuroimmunomodulation 1: 181-187.

Zalutsky, R.A. and Nicoll, R.A. 1990. Comparison of two forms of long-term potentiation in single hippocampal neurons. Science 248: 1619-1624.

Zhang, L., Ruehr, M.L., and Dorman, R.V. 1996. Arachidonic acid and oleoylacetylglycerol induce a synergistic facilitation of $\mathrm{Ca}^{2+}$-dependent glutamate release from hippocampal mossy fiber nerve endings. $J$. Neurochem. 66: 177-85.

Zhang S-C. and Fedoroff, S. 1997. Cellular localization of stem cell factor and $c$-kit receptor in the mouse nervous system. J. Neurosci. Res. 47: 1-15.

-1998. Modulation of microglia by stem cell factor. J. Neurosci. Res. 53; 29-37.

Zsebo, K.M., Williams, D.A., Geissler, E.N., Broudy, V.C., Martin, F.H., Atkins, H.L., Hsu, R.Y., Birkett, N.C., Okino, K.H., Murdock, D.C., et al.. 1990a. Stem cell factor is encoded at the $S l$ locus of the mouse and is the ligand for the c-kit tyrosine kinase receptor. Cell 63: 213-224.

Zsebo, K.M., Wypych, J., McNiece, I.K., Lu, H.S., Smith, K.A., Karkare, S.B., Sachdev, R.K., Yuschenkoff, V.N., Birkett, N.C., Williams, L.R., et al. 1990b. Identification, purification, and biological characterization of hematopoietic stem cell factor from Buffalo rat liver-conditioned medium. Cell 63: 195-201.

Received May 24, 2000; accepted in revised form September 29, 2000.

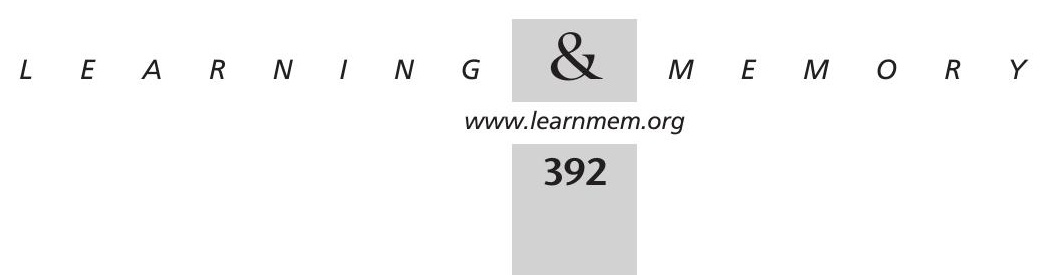




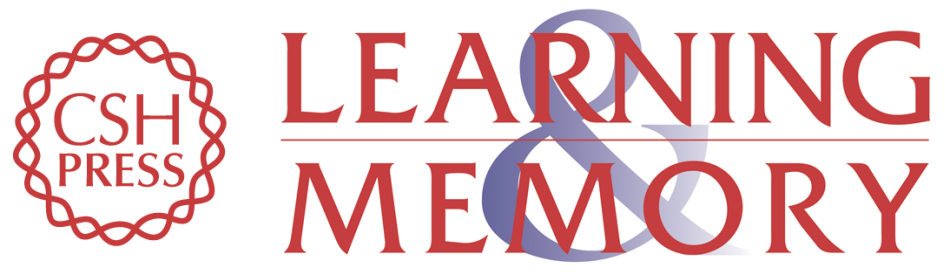

\section{Impairment of Spatial Learning and Hippocampal Synaptic Potentiation in c-kit Mutant Rats}

Toshihiko Katafuchi, Ai-Jun Li, Seiichi Hirota, et al.

Learn. Mem. 2000, 7:

Access the most recent version at doi:10.1101/lm.33900

References This article cites 41 articles, 11 of which can be accessed free at: http://learnmem.cshlp.org/content/7/6/383.full.html\#ref-list-1

License

Email Alerting Receive free email alerts when new articles cite this article - sign up in the box at the Service top right corner of the article or click here. 